\title{
Risk and Triggering Factors Associated with Bronchial Asthma Among School-Going Children in an Urban City of Coastal Karnataka
}

\section{Kamath SP1, Shrishakumar $\mathrm{S}^{2}$, Jain $\mathrm{A}^{3}$, Ramakrishna $\mathrm{A}^{4}$, Baliga SB ${ }^{5}$}

\begin{abstract}
Introduction: Asthma is common in childhood and is a major public health issue. The objectives of this study were to identify risk and triggering factors associated with asthma among school children. Material and Methods: A prospective cross sectional study was conducted among 6-15 years old children, over two months in two private schools at Mangalore city. Trigger factors were assessed as per asthma trigger inventory (ATI). Responses were graded from 0-5 score based on 'never', 'rarely', 'sometimes', 'most of the time' and 'always'. A predesigned questionnaire suiting the city environment was prepared and used to assess the risk and triggering factors. Analysis was done using SPSS version 16. Results: Asthma and allergic rhinitis in parents $(34.1 \%, 40.7 \%)$,smoking at home(24.2\%), exclusive breast feeding absence (27.5\%), early weaning $(24.2 \%)$, living in a flat $(37.4 \%)$ and pets at home(37.4\%) were risk factors noted. As per ATI, it was found that 'having a cold' was the most frequently selected trigger at $94.5 \%(47.3 \%$ 'sometimes', $2.2 \%$ 'always'), followed by 'running' at $79.1 \%$ (27.5\% 'sometimes', $13.2 \%$ 'always'), and 'house dust' at $69.2 \%$ (31.9\% 'sometimes', 6.6\% 'always'). The highest mean was for infections, $(2.228, \mathrm{SD}=0.546)$, followed by physical exercise $(2.167, \mathrm{SD}=0.331)$. Animal allergens had lowest mean $(1.527, \mathrm{SD}=0.104)$, followed by psychological triggers at second lowest $(1.579, \mathrm{SD}=0.181)$. However none of the risk and trigger factors had statistical significance with asthma. Conclusion: Avoiding exposure to probable triggers and identifying risk factors would aid in planning effective strategic measures with better quality of life.
\end{abstract}

Key words: allergens, asthma, questionnaire, risk factors, smoke

\section{Introduction}

In India, prevalence of asthma ranges from $0.2 \%$ to $31.1 \% .{ }^{1}$ Asthma, is hyper responsiveness of airways and is immunologically mediated through allergens / respiratory irritants. Assessing risk factors and triggers is necessary to optimise management. Various studies have documented risk factors association with occurrence of asthma in school going children. ${ }^{2,3,4,5}$ Asthma exacerbations by specific trigger
${ }^{1}$ Dr. Sowmini P Kamath, MBBS, MD, Associate Professor, Department of Paediatrics.ORCID iDhttps://orcid.org/0000-0001-7902-1012, ${ }^{2} \mathrm{Dr}$. Shrividya Shrishakumar, MBBS. Department of Paediatrics, ${ }^{3} \mathrm{Dr}$. Animesh Jain, MBBS, MD, Professor and Head, Department of Community Medicine. ORCID iDhttp://orcid.org/0000-00030250-3608, ${ }^{4} \mathrm{Dr}$. Anand Ramakrishna, MBBS, MD, Professor, Department of Pulmonary Tuberculosis and Chest Diseases (PTCD), ${ }^{5} \mathrm{Dr}$. Shantharam B Baliga, MBBS, MD, Professor, Department of Paediatrics, Kasturba Medical College, Manipal University, Mangalore, India. All from the Kasturba Medical College, Manipal University, Mangalore, India.

\section{Address for correspondence}

Dr. Sowmini P. Kamath, Associate Professor, Department of Paediatrics,

Kasturba Medical College

Light house hill road, Mangalore -575 001, Karnataka, India

Tel No; +91(0824) 2422271

E-mail: kamathsowmini@yahoo.com

Acknowledgements: We thank the school children and their parents/guardians who participated in this study and the block education officer and respective school authorities for permitting us to conduct this study. Our sincere thanks to MS Kotian, who helped us in analysing the data.

Funding: Nil

Conflict of Interest: None

Permission from IRB: Yes

How to cite

Kamath SP, Shrishakumar S, Jain A, Ramakrishna A, Baliga SB. Risk and Triggering Factors Associated with Bronchial Asthma Among School-Going Children in an Urban City of Coastal Karnataka. J Nepal Paediatr Soc 2017;37(1):59-66.

doi: http://dx.doi.org/10.3126/jnps.v37i1.16634

This work is licensed under a Creative Commons Attribution 3.0 License.

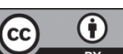


factors are a well-known fact and how it affects their quality of life have been studied by Luskin AT et $\mathrm{al}^{6}$. Asthma exacerbations by asthma trigger factors have been documented by few studies ${ }^{7,8,9,10,11}$. This study was undertaken to identify the risk and trigger factors of asthma among school children of urban Mangalore.

\section{Material and Methods}

All the private schools in Mangalore were listed and two schools (both Kannada and English medium) were selected based on convenience of travel. It was a cross sectional study conducted over two month's duration. Permission was obtained from the Block Education Officer and respective school authorities. Informed consent was obtained from parents/guardians. Institutional ethics committee approval was obtained.

All children aged between 6 to 15 years, studying in classes I-X, and present in class on the day of distribution, were given the questionnaire and included in the study. Subjects who refused to participate in the study were excluded. The prevalence of asthma was determined using the standard ISAAC questionnaire ${ }^{12}$. The objective of the study was to determine risk factors and triggers associated with asthma using a structured and pre-designed questionnaire. The sample size was calculated at 1216 assuming the prevalence of asthma at $8 \%,{ }^{2}$ at $95 \%$ confidence interval $(\mathrm{Cl}), 80 \%$ power, and non-response rate of $10 \%$.

Asthma Trigger Inventory $(A T I)^{13}$ :It is a reliable and valid questionnaire inventory that identifies the impact of triggers on daily life and perceived control over the triggers both during initial screening and at subsequent follow-ups. As per ATI, the 32 trigger factors have been organized into six subscales viz., exercise, animal allergens, psychological, pollen allergens, infections, and irritants. Psychological subscale included feeling tense, being excited, feeling alone, being angry, depressed mood, arguments, stress at home, unhappiness, intense worries and feeling weak. Feathers from birds, cats and animal hair, were assessed as animal allergens. Pollen allergens were either pollen from trees/flowers, grass or from weeds. Climbing stairs, running, bicycle, riding, sports, overexertion was included in the exercise subscale. Air pollutants/irritants included exposure to house dust, strong smells, smell of paint, perfumes, sprays, cigarette smoke and exhaust fumes. Having a cold flu, sinus problems and viruses were assessed in the infectious subscale. Responses to ATI, which describes how often each trigger causes an attack of asthma, in an individual patient were marked on a scale from 1 to 5 ,exposure ranging from getting 'never exposed' to 'always exposed',(1=Never,2=Rarely,3=So metimes, $4=$ Most of the time,5=Always $)^{13}$.
In addition, we prepared a self-structured questionnaire enumerating the most common triggers relevant to this locality. Based on this additional questionnaire, trigger factors perceived were categorized as pollutants and chemicals, weather and climate, environment and food products categories.

ISAAC asthma Core Questionnaire ${ }^{12}$ was used for assessing the asthma prevalence. A self-structured supplementary questionnaire was used to assess the prevalence of risk factors ${ }^{14}$. Perceived triggers of asthma as per Asthma trigger inventory ${ }^{13}$ and as per self-structured questionnaire prepared suiting the city environment was collected. Questionnaires in both English and Kannada (local language) versions were used for the study. The versions in Kannada were translated back into English to ensure reliability and validity. The respective parents/guardians with their consent answered the questionnaires at their respective homes. The answered questionnaires were collected the next day from the respective class-teachers.

\begin{tabular}{|c|c|}
\hline \multicolumn{2}{|c|}{ Operational definitions: ${ }^{15,16}$} \\
\hline Current wheezers & $\begin{array}{l}\text { Child with symptom of wheezing / } \\
\text { whistling in the past } 12 \text { months. }\end{array}$ \\
\hline Severe asthma & $\begin{array}{l}\text { Anybody with }>4 \text { attacks of } \\
\text { wheeze in the past } 12 \text { months, } \\
\text { or sleep disturbance for one/ } \\
\text { more than one night per week, } \\
\text { or speech limitation because of } \\
\text { wheeze in the past } 12 \text { months, } \\
\text { was categorized as having } \\
\text { Severe asthma categories. }\end{array}$ \\
\hline Risk factor & $\begin{array}{l}\text { Any attribute, characteristic } \\
\text { or exposure of an individual } \\
\text { that increases the likelihood of } \\
\text { developing asthma attack. }\end{array}$ \\
\hline Trigger factors & $\begin{array}{l}\text { Factors/agents that might trigger } \\
\text { asthma attack in an asthmatic } \\
\text { subject. }\end{array}$ \\
\hline
\end{tabular}

Statistical analysis: Analysis was done using SPSS (Statistical Package for Social Sciences) version 16. The results were expressed as means of rates and proportions. The mean, median and standard deviations among the six subscales were calculated. Any significant association was determined by applying the Chi-square test. A $p$-value $<0.05$ was taken as statistically significant.

\section{Results}

A total of 1011 responses (83.14\% response rate) were included. Prevalence of current wheezers was 9 $\%$ (91/1011) with severe symptoms being present in $28.6 \%(26 / 91)$, indicating severe asthma in $2.6 \%$ of the study population. Current wheezers were subjected to 
the supplementary questionnaire to assess risk factors and triggers.

Table 1 shows the prevalence of risk factors. Having a cold (47.3\%), running $(27.5 \%)$, being angry (27.5\%), strong smells (28.6\%) and house dust(31.9\%), were the triggers which 'sometimes' triggered an attack in an individual. Having a cold (25.3\%), sport activities (12.1) and being excited (8.8\%) triggered attacks most of the time. Running (13.2\%) and climbing stairs (14.3\%) always triggered attacks.

Figure 1 illustrates the frequency of the presence of different triggers as per ATI (has been calculated by excluding 'never' category and taking the rest of the categories to imply presence of the trigger).

Median and mean values of each subscale of ATI were calculated. In the median format, having a cold was the only trigger with a median of 'most of the time' with a standard deviation of 0.876 . Table 2 shows the mean values for each of the subscales. The highest mean was for the infections subscale (2.228), and the least for the animal allergen subscale (1.527).
In current wheezers, mainly fire wood use (53.8\%), tobacco snuff (40\%), summer and rainy season (56\%), carpets and soft toys (56\%), presence of insects and bugs $(67 \%)$, eating fruits $(66.7 \%)$, and pulses $(75 \%)$ triggered severe symptoms. No significant association was observed for any of the triggers with severe asthma.

Figure 2 enumerates frequency of common triggers. In the category of pollutants and chemicals, the highest percentage was for firecrackers at $49.5 \%$. This was followed by factory smoke $(29.7 \%)$ and firewood smoke (14.3\%). In the weather and climate category, the highest prevalence was for rainy and winter seasons at $74.7 \%$ and $71.4 \%$ respectively. It was followed by travel to hilly areas at $35.2 \%$. In the environment category, the highest values were observed for mosquito coil smoke $(46.2 \%)$, followed by chalk dust $(35.2 \%)$, cotton bedding $(34.1 \%)$, dampness/wet surroundings, moulds/fungus in damp places, use of agarbhattis/incense sticks and air conditioners (30\% each). The food products category led with fish/shellfish and seafood at $29.7 \%$ followed by groundnuts and peanuts at $23.1 \%$, packed fried items at $22 \%$, Chinese food, chocolates and chocolate drinks at $21 \%$.

Table 1: Risk factors present in the current wheezers $(n=91)$

\begin{tabular}{lc}
\hline Risk factors & Number (\%) \\
\hline Asthma in parents & $36(34.1)$ \\
\hline Allergic rhinitis in parents & $37(40.7)$ \\
\hline Atopic dermatitis in parents & 0 \\
\hline Smoking mother & $16(17.6)$ \\
\hline Smoking father & $6(6.6)$ \\
\hline Other smoking family member & $25(27.5)$ \\
\hline No exclusive breast feeding (4-6 months) & $22(24.2)$ \\
\hline Early weaning (<4 months) & $6(6.6)$ \\
\hline Unclean residential surroundings & $34(37.4)$ \\
\hline Living in a flat & $37(40.7)$ \\
\hline Living in a covered house & $23(25.3)$ \\
\hline Carpets at home & $17(18.7)$ \\
\hline Pets at home & \\
\hline
\end{tabular}

Table 2: Mean and standard deviations among the six subscales of ATI

\begin{tabular}{ccc}
\hline Subscale & Mean & StandardDeviation (SD) \\
\hline Psychological & 1.579 & 0.181 \\
\hline Animal allergens & 1.527 & 0.104 \\
\hline Pollen allergens & 1.432 & 0.112 \\
\hline Exercise & 2.167 & 0.331 \\
\hline Irritants & 1.816 & 0.269 \\
\hline Infections & 2.228 & 0.546 \\
\hline
\end{tabular}




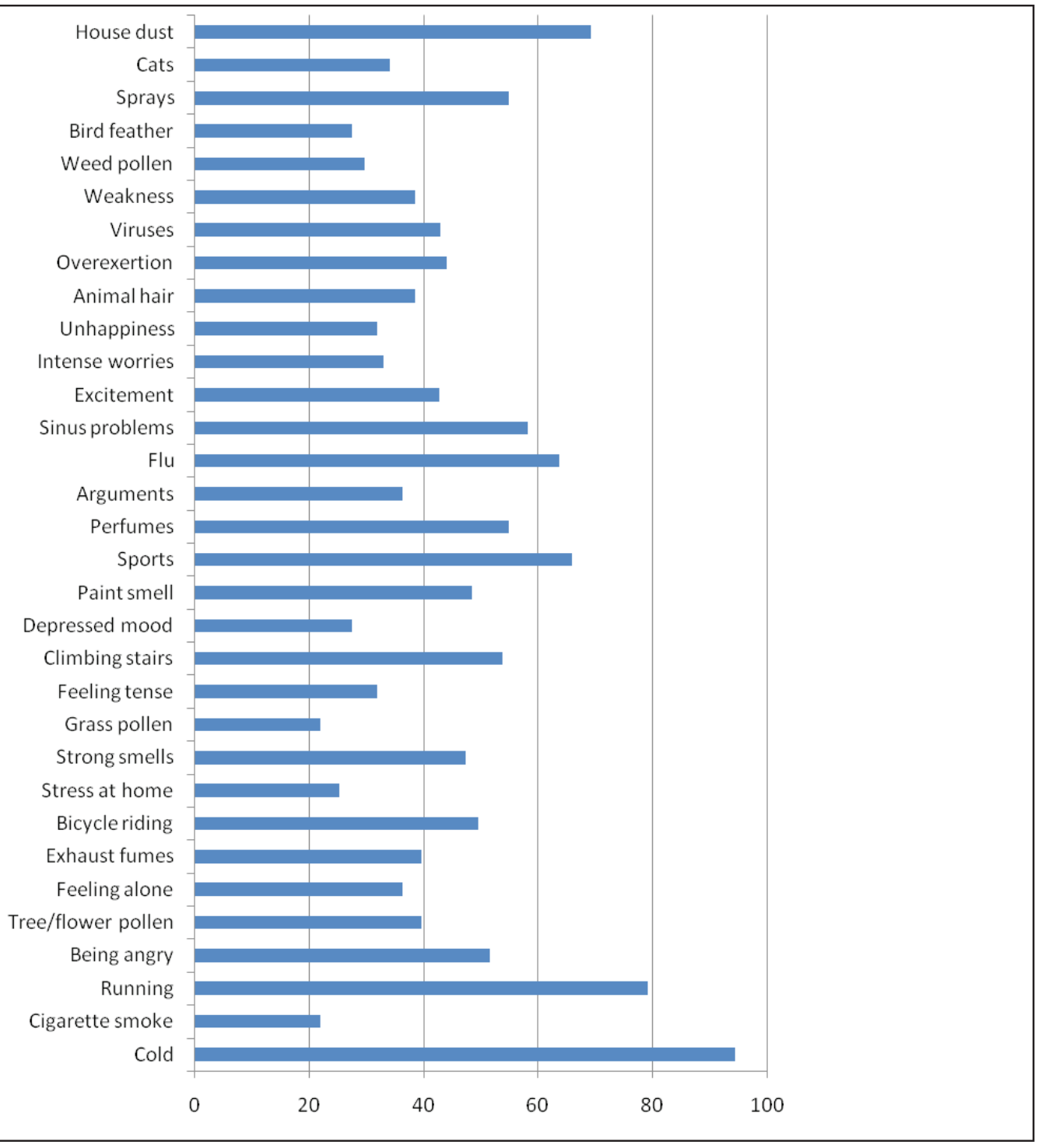

Fig 1: Percentage frequency of perceived asthma triggers in the Asthma Trigger Inventory (ATI)

\section{Discussion}

Risk factors:Among risk factors assessed, in current wheezers, allergic rhinitis and asthma in parents were the most prevalent. Similarly a positive family history of allergy/asthma were significantly associated risk factors for asthma as in studies by Mathew AC et all. [OR3. 10 in 5-10 years and OR 2.99 in 11-15 years, $p=0.0001)^{3}$, by Cheraghi $\mathrm{M}$ et al (OR 6.55; $p=<0.0001)^{4}$, by Majeed R et. al. (OR 26.8; $p<0.0001)^{14}$, and by Chhabra SK et $\mathrm{al}(p<0.01)^{17}$. Study by Jain A et $\mathrm{al}^{18}$, had documented prevalence of asthma to be almost thrice (18.8\%) among children with a family history of asthma when it was compared to those with absent family history of asthma (6.3\%), the association being significant. Abdallah AM et al $^{19}$ in his study on Egyptian children also found a significant association between positive family history of allergy/ allergic diseases and asthma. Thus; it demonstrates genetic influence on the disease.
Inadequate ventilation at residing places and the occurrence of asthma have significant association as in studies by Mathew AC et al (OR 4.94, in 11-15 years, $p=0.001)^{3}$ and by Pokharel PK et al with absence of windows in living rooms (OR 4.03; $p=0.041)^{20}$. In our study, $40.7 \%$ of children lived in such houses and no significant association was found with asthma.

Smoking by parents and household members results in passive smoking. Significant association was found between asthma attacks and the exposure to passive smoking by Cheraghi $\mathrm{M}$ et al (OR 1.48; $p=0.002^{4}$, by Chhabra SK et al $(p<0.01)^{17}$, and by Pokharel PK et. al. $(O R \text { 3.33; } p=0.004)^{20}$. Majeed $R$ et $a^{14}$, and Verma $\mathrm{R}$ et.al. ${ }^{21}$, had reported $38.5 \%$ and $39 \%$ of subjects in their studies respectively to be subjected to passive smoking. Nearly one fourth of children $(24.2 \%)$ in our study were subjected to passive smoking, but there was no statistically significant association with asthma. 


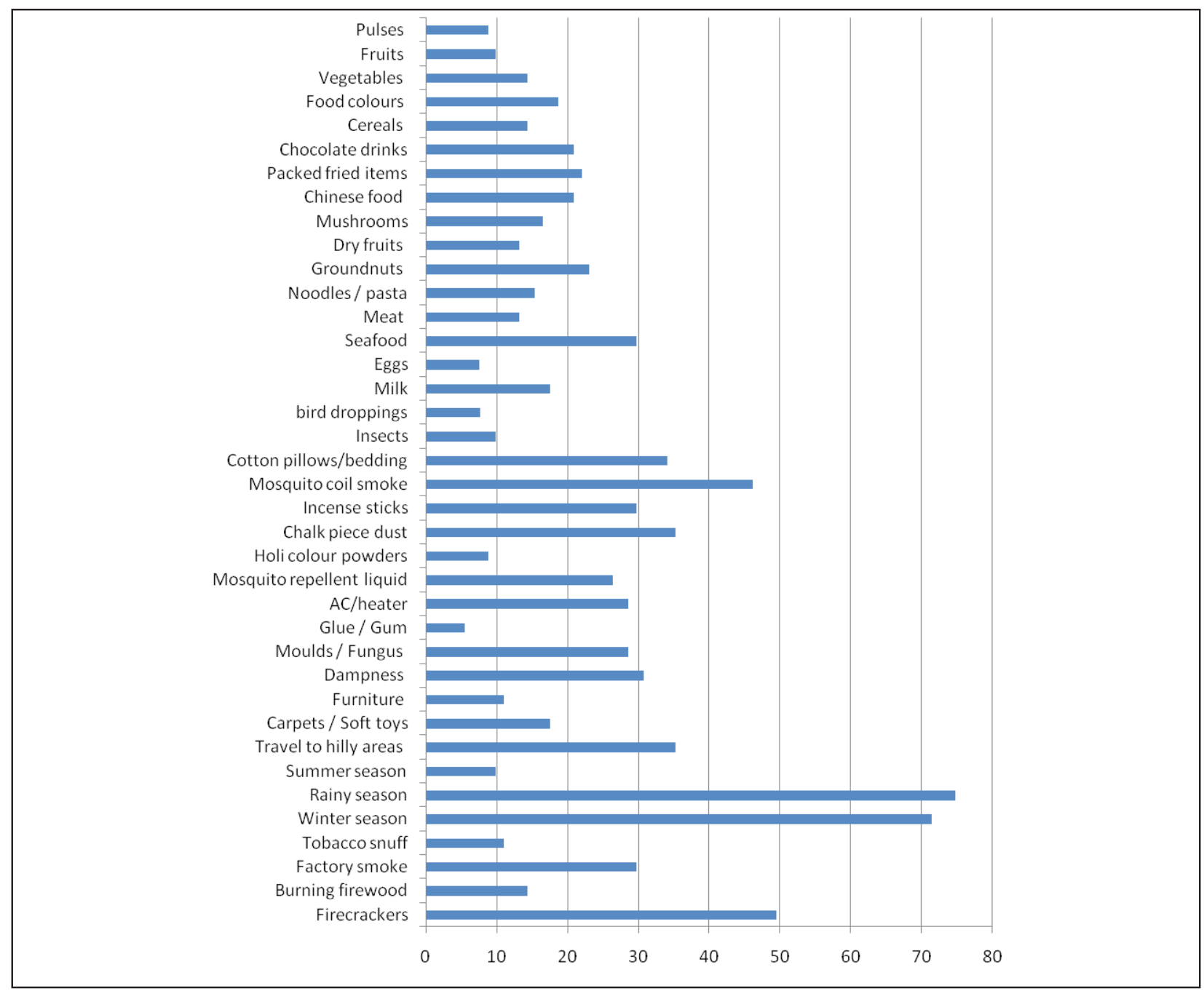

Fig 2: Percentage (\%) prevalence of common asthma triggers as per structured questionnaire suiting the city

This may probably be due to under reporting of smoking habits due to social stigma.

High rise commercial and residential buildings in the city, with multiple stories, provide an easy shelter for birds-especially pigeons, to roost and nest. A study by Curtis $L$ et. al. conducted in Chicago determined that considerable quantities of pigeon allergens can be present in wild pigeon infested environments in which pigeons are not kept indoors ${ }^{22}$. The allergenic proteins are found in bird droppings, serum, feathers, skin scales and pigeon bloom. Positive IgE antibody reactions to droppings, feathers and to sera have been found among subjects with Bird Fancier's Asthma ${ }^{23}$. Pigeon allergens may play an important role in worsening asthma in certain urban environments where they harbour, as was observed by Deo $S$ et. al. in a study in Mumbai, which showed increased circulating IgG antibody levels to pigeon dropping antigens and an increase in hypersensitivity reactions to pigeon allergens among the participants ${ }^{24}$. Around $38 \%$ of asthmatics were residing in flats in our study, however no significant association was found.

Lodge $\mathrm{CJ}$ et. $\mathrm{al}^{25}$. in his systematic review and meta-analysis study of 89 articles regarding association between breastfeeding and childhood allergic diseases concluded that there is some evidence that breastfeeding is protective for asthma (5-18 years), with weaker evidence for a protective effect for eczema $\leq 2$ years and allergic rhinitis $\leq 5$ years of age, with greater protection for asthma and eczema in low-income countries. Similarly as per 2006 Aboriginal Children's Survey $(n=14,170)$, conducted by Ming Ye et $\mathrm{al}^{26}$, exclusive breastfeeding was protective of asthma, when compared with non- breastfeeding (OR 0.59; $p<0.0001$ ) children. In our study, exclusive breast-feeding was practiced by mothers in $72.5 \%$ children and was not associated with asthma. 
WHO, in the current guidelines, advocated exclusive breast-feeding for the first six months, but a few scientists believe that introducing potential trigger foods before six months while continuing breast feeding, could protect children against developing allergies (repeated exposure of the immune system at an early age to an allergenic food primes the body to tolerate and does not cause allergy as the child grows older). Anderson HR et. al. ${ }^{27}$ in his review article has shown dramatic increase in asthma, eczema in the United Kingdom since 1955 , while Venter $\mathrm{C}$ et $\mathrm{a}^{28}{ }^{28}$, documented an increase in the peanut allergy rates. This has coincided with two third reductions in early weaning. Therefore, it was postulated that late introduction of food could promote food allergies. This led to a research question-Is early weaning an effective approach or not, to prevent food allergy in young children? The Enquiring about Tolerance (EAT) study team by Perkin MR et $\mathrm{al}^{29}$, conducted a trial with early introduction of six allergenic foods (cow's milk, sesame, cooked egg, peanut, wheat and whitefish) at three months of age. It concluded, that early introduction of multiple allergenic foods in normal breast-fed infants prevent food allergy to certain extent and may be dependent on adherence and dose of allergens introduced during the weaning process. Similarly Tromp II et. al. ${ }^{9}$ conducted a populationbased prospective cohort study( $n=6905$ children) in Netherlands and documented wheezing in $31 \%$ at age 2 years and in $14 \%$ at ages three and four years, while eczema was reported in $38 \%, 20 \%$, and $18 \%$ of children at the ages of 2, 3, and 4 years, respectively. He found that the introduction of peanuts, tree nuts, hen's egg, cow's milk, gluten and soy before the age of 6 months was not significantly associated with eczema or wheezing $^{9}$. Early weaning had occurred in nearly one fourth(24.2\%) of our children, and had no association with asthma occurrence.

Pokharel PK et al in his study showed significant association between the pets (dogs and cats) at home and the asthma attacks (OR $5.5 ; p=0.045)^{20}$. Verma $R$ et. al. ${ }^{21}$ reported $35 \%$ of asthmatics had pet animals at home. In our study, $18.7 \%$ of current wheezers had pets at home with no significant association with asthma.

Trigger factors: The Asthma Trigger Inventory was first developed by Ritz et. al ${ }^{13}$. for adults, but proved to be perfectly reliable and valid for use in the paediatric population by Wood BL et. $\mathrm{al}^{30}$. was answered by our study population. 'Having a cold' was the most frequent trigger $(94.5 \%)$, with $47.3 \%$ stating it triggers their asthma 'sometimes' and about $2.2 \%$ saying it 'always' triggers an attack followed by 'running' at $79.1 \%$ (27.5\% 'sometimes', 13.2\% 'always') and 'house dust' at 69.2\% (31.9\% 'sometimes', 6.6\% 'always'). As per Ritz et al ${ }^{13}$, of the six relevant categories of ATI, the most frequently mentioned categories were climate, air pollution/irritants and physical activity. These were reported by more than fifty percent of patients $(n=247)$ as one major trigger, while at least one psychological trigger was mentioned by approximately one fourth of cases. According to Abdallah AM et. al. ${ }^{19}$ exposure to dust (84.6\%), playing, physical activity (58.5\%), and common cold attacks $(56.9 \%)$ were the most common triggering factors for asthma exacerbations. Trigger identification has a crucial role in asthma diagnosis and management. Evaluation of triggers exposure would guide the asthmatic patients to avoid implicated triggers for their attacks and thereby improve their quality of life ${ }^{13}$.

The mean and standard deviation values of the trigger subscales of ATI in our study had consistent values similar to a study by Wood $B L$ et $a^{30}{ }^{30}$, [in his study, means from highest to lowest were as follows: infections' category (2.33 \pm 1.04$)$, physical exercise category (2.01 \pm 0.86 ), animal allergens $(1.38 \pm 1.27)$ and psychological factors $(0.76 \pm 0.77)]$.

Relevant to this urban city, most common triggers were rainy season $(74.7 \%)$ and winter season $(71.4 \%)$, followed by firecrackers $(49.5 \%)$ and mosquito-coil smoke $(46.5 \%)$. Similarly, in a study by Pradeepa $\mathrm{PN}$ et. $\mathrm{al}^{31}$. asthma exacerbations were higher in the rainy season (June-6.3\% and July $-5.8 \%$ ), the climatic conditions being similar to Mangalore city. Dampness, fungus and moulds are rampant in these areas since it is a coastal area with high humidity; in our study 59.4 $\%$ of current wheezers lived in such surroundings. As per the study by Cheraghi $\mathrm{M}$ et $\mathrm{al}^{4}$, the presence of dampness (OR: 1.59, p<0.0001) at home was significantly associated with asthma. Consumption of pasta/noodles, Chinese food and packed fried items ( $15.4 \%$ to $22 \%$ ) was similar to the rates described in the study by Awasthi et.al. $(16.4 \%)^{32}$.

Mangalore is endemic to malaria and dengue attacks, thus there is usage of either mosquito coil smoke or repellent in almost all the houses. In our study, $26.4 \%$ and $46.2 \%$ of current wheezers were triggered with use of repellent liquid and coil smoke respectively. Sharma VP ${ }^{33}$, reported symptoms of asthma in $0.47 \%$ $(28 / 5920)$ of interviewed symptomatic subjects because of using mosquito repellents. Kumar R et. al. ${ }^{8}$ monitored mean concentrations of particulate matter during the pre-burning, burning and post burning phases of mosquito coil in the indoor environment and found it to be $259.2 \mu / \mathrm{m} 3,232.4 \mu / \mathrm{m} 3$ and $214.0 \mu / \mathrm{m} 3$ respectively and concluded there is emission of respirable particulate matter on burning mosquito coil in the indoor environment, which may accumulate overtime and lead onto respiratory illnesses. 
Luskin AT et. al. ${ }^{6}$ in his study demonstrated in severe asthmatics, exacerbation rates and asthma related quality of life could be improved with avoidance of asthma triggers. Six asthma triggers viz., emotional stress, cold and/or sinus infection, pollens, animals, mould and /or dampness and dust were assessed in his study. As the number of asthma triggers at baseline increased, the total number of exacerbations increased. On univariate analysis, all triggers were significantly predictive for asthma exacerbations, except for pollen and animals. In multivariate analysis, cold and /or sinus infections were most strongly predictive of asthma exacerbations (OR 1.55, $p<0.001$ ) followed by emotional stress (OR 1.42; $p<0.001$ ), mould and/or dampness (OR 1.21; $p=0.03$ ).Dust, animals, and pollen showed nosignificant association ${ }^{6}$.

Peterson MG et. al. ${ }^{34}$ found that those patients with exposure to greater number of trigger factors had poorer asthma outcomes. There is improvement in asthma control with reduction in medical needs, if patient exposure to few categories of triggers/risk factors is minimized as stated by current asthma guidelines ${ }^{35}$.

Thus, trigger identification is vital in guiding patient and caretaker to reduce the chronic burden caused on their daily life thereby improving the quality of life. Avoidance of asthma triggers needs to be emphasized to patients by the treating physicians. Along with this, treatment as per protocol guidelines to control asthma and prevent exacerbations targeting to improve their quality of life should be the main aim of the physician. School absenteeism, refraining from physical training period and games would decrease. Academic performance and self-esteem in children would improve.

The study had few limitations. Causal association of various risk and trigger factors with asthma could not be ascertained since it was a cross sectional study. The responses to the questionnaire might have been affected by recall bias. Comprehension of questions may not be uniform in the study population. Since asthma is considered a social stigma, this may lead to underreporting. Another limitation of this study is that the risk factors like past history of bronchiolitis, premature delivery, and previous history of mechanical ventilation were not assessed. Physical examination, PEFR, and spirometry were not done as it was beyond the scope of the study due to feasibility constraints.

\section{Conclusion}

For childhood asthma, most prevalent risk factors were family history of allergic rhinitis/ asthma, and living in urban areas. Commonly perceived triggers (as per ATI) were highest in infections and exercise group. Most prevalent triggers in the area were exposure to rainy/ winter seasons, firecrackers and mosquito coil smoke. Identifying risk factors and triggers would aid treating paediatricians in better understanding of disease and individualisation of treatment.

\section{References}

1. Pal R, Dahal S, Pal S. Prevalence of bronchial asthma in Indian children. Indian JComm Med 2009;34:310-6.

2. Sharma BS, Kumar MG, Chandel R. Prevalence of asthma in urban school children in Jaipur, Rajasthan. Indian Pediatr 2012;49:835-6.

3. Mathew AC, Prince TG, Remees R, Saravanapandian N, Ramalingam S, Srikanth K et al. Prevalence and Risk Factors of Asthma in School Going Children in South India. Nepal J Epidemiol 2012;2:171-8.

4. Cheraghi M, Dadgarinejad A, Salvi S. A cross-sectional study to find prevalence and risk factors for childhood asthma in Pune City, India. ISRN Public Health. 2012; 12:361456. doi: 10.5402/2012/361456.

5. Kumar GS, Roy G, Subitha L, Sahu SK. Prevalence of bronchial asthma and its associated factors among school children in urban Puducherry, India.J Nat ScBiol Med 2014;5:59-62.

6. Luskin AT, Chipps BE, Rasouliyan L, Miller DP, Haselkorn T, Dorenbaum A. Impact of asthma exacerbations and asthma triggers on asthma-related

quality of life in patients with severe or difficult-to-treat asthma. J AllergyClinImmunolPract 2014;2:544-52.

7. Chilmonczyk B, Salmun L, Megathlin K, Neveux L, Palomaki G, Knight $G$ et al. Association between Exposure to Environmental Tobacco Smoke and Exacerbations of Asthma in Children. NEngl J Med 1993;328:1665-9.

8. Kumar R, Kumar D, Kumar M, Mavi A, Singh K, Gupta $\mathrm{N}$. Monitoring of indoor particulate matter during burning of mosquito coil, incense sticks and dhoop. Indian J Allergy Asthma Immunol2014;28:68-73.

9. Tromp II,Kiefte-de Jong JC, Lebon A, Renders CM, Jaddoe VWV, Hofman A et al. The introduction of allergenic foods and the development of reported wheezing and eczema in childhood: The Generation $\mathrm{R}$ Study. ArchPediatrAdolesc Med 2011;165:933-8.

10. Trompll, Kiefte-de Jong JC, de Vries JH, Jaddoe VW, Raat H, HofmanA, et al. Dietary patterns and respiratory symptoms in pre-school children: the Generation R Study.EurRespir J 2012;40:681-9.

11. Kiefte-de Jong JC, de Vries JH, Franco OH, Jaddoe VW, Hofman A, Raat $\mathrm{H}$ et al. Fish consumption in 
infancy and asthma-like symptoms at preschool Age.Pediatrics2012; 130(6):1060-8. doi: 10.1542/ peds.2012-0875. Epub 2012 Nov 12.

12. Pearce N, Ait-Khaled N, Beasley R, Mallol J, Keil U, Mitchell E,Robertson C;ISAAC Phase three study group. Worldwide trends in the prevalence of asthma symptoms: phase III of the International Study of Asthma and Allergies in Childhood (ISAAC). Thorax 2007;62:758-66.Epub 2007 May 15.

13. Ritz T, Steptoe A, Bobb C, Harris AH, Edwards M. The asthma trigger inventory: validation of a questionnaire for perceived triggers of asthma. Psychosom Med 2006;68:956-65.

14. Majeed R, Rajar UD, Shaikh N, Majeed F, Arain AA. Risk Factors Associated with Childhood Asthma. J CollPhysicians Surg Pak 2008;18:299-302.

15. Anderson HR, Gupta R, Kapetanakis V, Asher MI, Clayton T, Robertson CF, Strachan DP. ISAAC Steering Committee. International correlations between indicators of prevalence, hospital admissions and mortality for asthma in children. IntJ Epidemiol 2008;37:573-82.

16. Lai CK, Beasley R, Crane J, Foliaki S, Shah J, Weiland S. International Study of Asthma and Allergies in Childhood Phase Three Study Group. Global variation in the prevalence and severity of asthma symptoms: Phase Three of the International Study of Asthma and Allergies in Childhood (ISAAC). Thorax 2009;64:47683.

17. Chhabra SK, Gupta CK, Chhabra P, Rajpal S. Risk factors for development of bronchial asthma in children in Delhi. Ann Allergy Asthma Immunol1999;83:385-90.

18. Jain $A$, Vinod Bhat $H$, Acharya $D$. Prevalence of bronchial asthma in rural Indian children: A cross sectional study from South India.Indian $J$ Pediatr 2010;77:31-5.

19. Abdallah A M, Sanusy KA, Said W S H, Mahran D G, Aliae $A R$ and Hussein M. Epidemiology of bronchial asthma among preparatory school children in Assiut district. Egypt J Pediatr Allergy Immunol 2012;10:109-17.

20. Pokharel PK, Pokharel P, Bhatta NK, Pandey RM, Erkki K. Asthma symptomatics school children of Sonapur. Kathmandu Univ Med J 2007;5:484-7.

21. Verma R, Khanna P, Chawla S, Singh R (2013). To Study the Incidence of Asthma among Children in a Rural Block of Haryana (India).2:604doi:10.4172/ scientificreports.604

22. Curtis L, Lee BS, Cai D, Morozova I, Fan JL, Scheff $P$ et al. Pigeon allergens in indoor environments: a preliminary study. Allergy 2002;57:627-31.
23. Tauer-Reich I, Fruhmann G, Czuppon AB, Baur X. Allergens causing bird fancier's asthma. Allergy 1994;49:448-53.

24. Deo S, NiphadkarPV,RameshS,Arora N, Kakade $\mathrm{AM}$, Mulay $\mathrm{C}$, et al. Identification of different pigeon allergens and its trigger toward increase in inner city Asthma. Indian J Allergy Asthma Immunol 2014;28:4046

25. Lodge CJ, Tan DJ, Lau MX, Dai X, Tham R, Lowe AJ et al. Breastfeeding and asthma and allergies: a systematic review and meta-analysis. ActaPaediatr 2015;104:3853

26. Ye M, Mandhane PJ, Senthilselvan A. Association of breastfeeding with asthma in young Aboriginal children in Canada. Can Respir J 2012;19:361-66.

27. Anderson HR, Gupta R, Strachan DP, Limb ES. 50 years of asthma: UK trends from 1955 to 2004. Thorax 2007;62:85-90.

28. Venter C, Hasan Arshad S, Grundy J, Pereira B,Bernie Clayton C, Voigt K, et al. Time trends in the prevalence of peanut allergy: three cohorts of children from the same geographical location in the UK. Allergy2010;65:103-8.

29. Perkin MR, Logan K, Tseng A, Raji B, Ayis S, Peacock J, Brough H, Marrs T, Radulovic S, Craven J, Flohr C, Lack G; EAT Study Team. Randomized trial of introduction of allergenic foods in Breast-fed infants. $N$ Engl J Med 2016;374:1733-43.

30. Wood BL, Cheah PA, Lim J, Ritz T, Miller BD, Stern $\mathrm{T}$, et al. Reliability and validity of the asthma trigger inventory applied to a pediatric population. $J$ PediatrPsychol 2007;32:552-60.

31. Narayana PP, Prasanna MP, Narahari SR, Guruprasad AM. Prevalence of asthma in school children in rural India. Ann Thorac Med 2010;5:118-9.

32. Awasthi S, Kalra E, Roy S, Awasthi S. Prevalence and risk factors of asthma and wheeze in schoolgoing children in Lucknow, North India. Indian Pediatr 2004;41:1205-10.

33. Sharma VP. Health hazards of mosquito repellantsand safe alternatives. CurrSci2001;80:341-343.

34. Peterson MG, Gaeta TJ, Birkhahn RH, Fernandez JL, Mancuso CA. History of symptom triggers in patients presenting to the emergency department for asthma.J Asthma 2012;49:629-36.

35. Bateman ED, Hurd SS, Barnes PJ. Bousquet J, Drazen JM, FitzGerald $M$ et al. Global strategy for asthma management and prevention. GINA executive summary. EurRespir J2008;31:143-78. 